\title{
Additional flap on plastic stents for improved antimigration effect in the treatment of post-cholecystectomy bile leak
}

\section{(이요}

\author{
Authors \\ Fogel $^{1}$, Lee McHenry ${ }^{1}$, Stuart Sherman ${ }^{1}$, Glen A. Lehman ${ }^{1}$ \\ Institutions \\ 1 Division of Gastroenterology/Hepatology, Indiana \\ University School of Medicine, Indianapolis, Indiana, \\ United States \\ 2 Current Affiliation: Digestive Disease Center, CHA \\ Bundang Medical Center, CHA University, Seongnam, \\ Republic of Korea
}

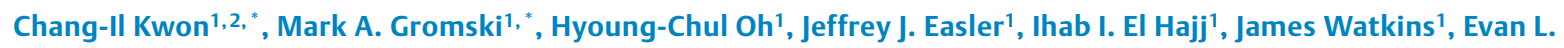

submitted 7.7.2017

accepted after revision 22.11.2017

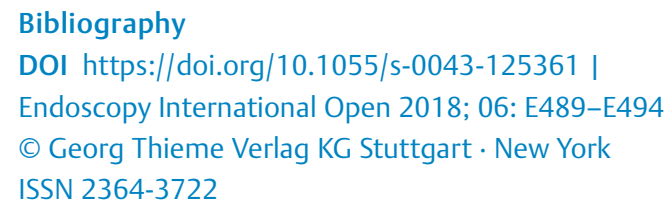

\section{Corresponding author}

Glen A. Lehman, MD, Indiana University Hospital, 550 North University Blvd., Suite 1634, Indianapolis, IN 46202-5149

Fax: +1-317-948-0164

glehman@iu.edu

\section{ABSTRACT}

Background and study aims In plastic stent insertion for treatment of post-cholecystectomy bile leak, stent migration may be more common due to the absence of a shelf to anchor the stent. We evaluated how adding a flap to straight plastic stents for this indication might influence the rate of stent migration when compared to use of conventional plastic stents.

Patients and methods This is a retrospective study including patients referred for ERCP for treatment of postcholecystectomy bile leak. Patients with a customized antimigration flap stent had the additional flap created on the distal end of straight plastic stents, intended to aid in anchoring in the distal supra-sphincteric biliary duct. The primary endpoint is stent migration events. The secondary endpoint is bile leak resolution after first ERCP session.

Results Thirty-two patients were treated with the experimental additional flap stents and 225 patients were treated with standard straight biliary stents. The total failure rate of bile leak resolution after a single endoscopic treatment for all treated was $10.5 \%(27 / 257)$ and the total stent migration rate for all enrolled was $15.2 \%$ (39/257). Stent migration rate was lower in the additional flap stent group than in the conventional group (3.1\% vs. $16.9 \%$, respectively, $P$ $=0.04)$. Furthermore, significantly more patients had resolution of their bile leak after the first ERCP session in the group with the additional flap ( $100 \%$ vs. $88 \%$, respectively, $P=0.03)$.

Conclusion A plastic biliary stent with an extra flap may have improved performance with regard to stent migration and resolution of bile leak over standard plastic biliary stents.

\section{Introduction}

Endoscopic biliary sphincterotomy and stent placement comprise an acceptable approach to the management of most cases of bile duct leak without associated additional injury [1]. Published reports of endoscopic therapy to treat bile leaks show an $88-100 \%$ success rate [ $2-7$ ]. The goal of endoscopic therapy is to eliminate the pressure gradient across the sphincter of Oddi, allowing transpapillary bile flow into the duodenum and avoiding extravasation from the leak site. The type of treat-

\footnotetext{
* Drs. Chang-Il Kwon and Gromski: These authors contributed equally.
}

ment pursued depends on the size of the leak, the location of the leak, the presence of a biloma and any retained stones or sludge $[2,8]$.

In stenting a biliary stricture, the stricture serves as an anchor point for the upstream flap on plastic stents, and helps prevent stent migration. In bile duct leaks without stricture, there is no such intrinsic anchor point, which may then predispose such stents to downward migration. Studies have reported a rate of migration for biliary stents of approximately $10 \%$, and a trend toward higher migration with sphincterotomy [9, 10]. Stent migration rates are rarely reported in series of bile leaks, with only one older report describing a rate of migration 


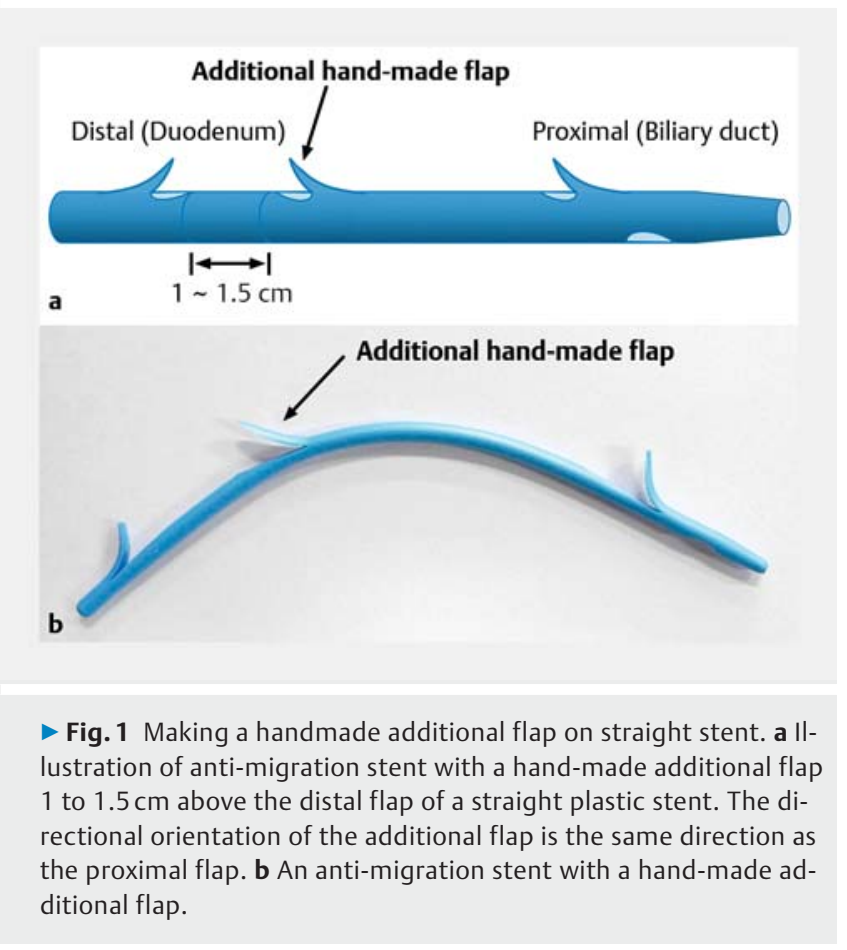

of $2.3 \%$ [5]. Anecdotally, we have noted higher rates of migration in bile leak patients, compared to stent placement for nonbile leak indications.

We hypothesized that creating an additional flap on the supra-sphincteric distal (downstream) end of the plastic stent may decrease the rate of duodenal migration for the treatment of bile leak. In this proof-of-concept study, we evaluate the efficacy and migration rate of stent placement with stents containing an additional "antimigration anchor flap" in patients with post-cholecystectomy bile leak.

\section{Patients and methods}

This is a retrospective case-control study of all patients between January 2006 and December 2016 who were treated with biliary stent insertion at endoscopic retrogradecholangiopancreatography (ERCP) for post-cholecystectomy biliary leaks at Indiana University Hospital. Inclusion criteria included: documented bile leak on index ERCP post-cholecystectomy and placement of a plastic biliary stent for the management of bile leak (either standard plastic stent or modified plastic stent with extra anti-migration flap). Exclusion criteria included: prior ERCP or stent placement at other hospital after cholecystectomy, early treatment failures within 7 days due to complicated problems, loss to follow-up (including stent removal after 150 days from stent placement), death prior to stent removal unrelated to stent, metal stent insertion or pig-tail stent insertion at time of ERCP.

For the modified stent, a scalpel was used to cut a flap no more than $40 \%$ deep into the diameter of the stent. If the stent flap is cut as such, no weakening is apparent. Stents are not difficult to deliver as there is usually no stricture. The additional flap was made $1-1.5 \mathrm{~cm}$ above the distal (duodenal) flap of a

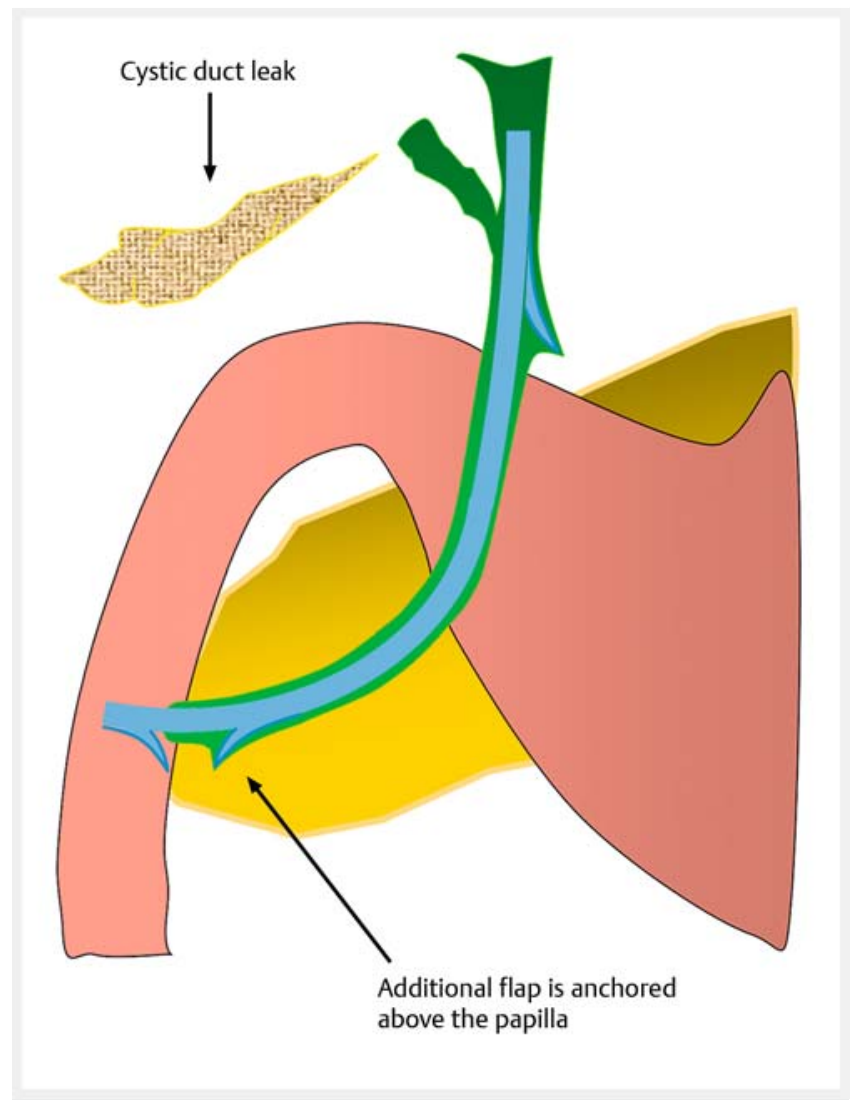

- Fig. 2 Illustration of stent insertion in patient with post-cholecystectomy bile leak. The patient usually has a non-dilated bile duct and no stenotic area, which can prevent stent migration. A handmade additional flap is anchored just above the ampulla.

straight plastic stent ( $>$ Fig.1). The directional orientation of the additional flap is the same direction as the proximal flap, intended to aid in anchoring in the distal supra-sphincteric biliary duct ( $>$ Fig.2). All ERCP endoscopists performed procedures for bile leaks using both conventional and the additional flap stents. There was no pre-specified patient selection criteria for which type of stent to deploy per patient, and was at the discretion of the endoscopist.

Post-cholecystectomy bile leaks were divided into two groups, as have previously been described in the literature [6, 11]: (1) simple bile leaks: leak from the cystic duct stump or cholecysto-hepatic Duct of Luschka; and (2) complex bile leaks: leak from major bile duct injury or combined with ductal stricture or complete transection of the bile duct. Healing of the bile leak was defined as resolution of a bile leak within typically 4 to 6 weeks after the first ERCP, without requiring further intervention (except for biliary stent removal in the resolved leak) [6, 7]. Standard protocol in our institution is to bring every bile leak patient back in 4-6 weeks from the index ERCP for biliary stent removal and cholangiogram to document either leak resolution or persistent leak. Early failure of the endoscopic treatment of biliary leak was determined by the need for further ERCP or intervention to control the bile leak within 7 days, and patients 


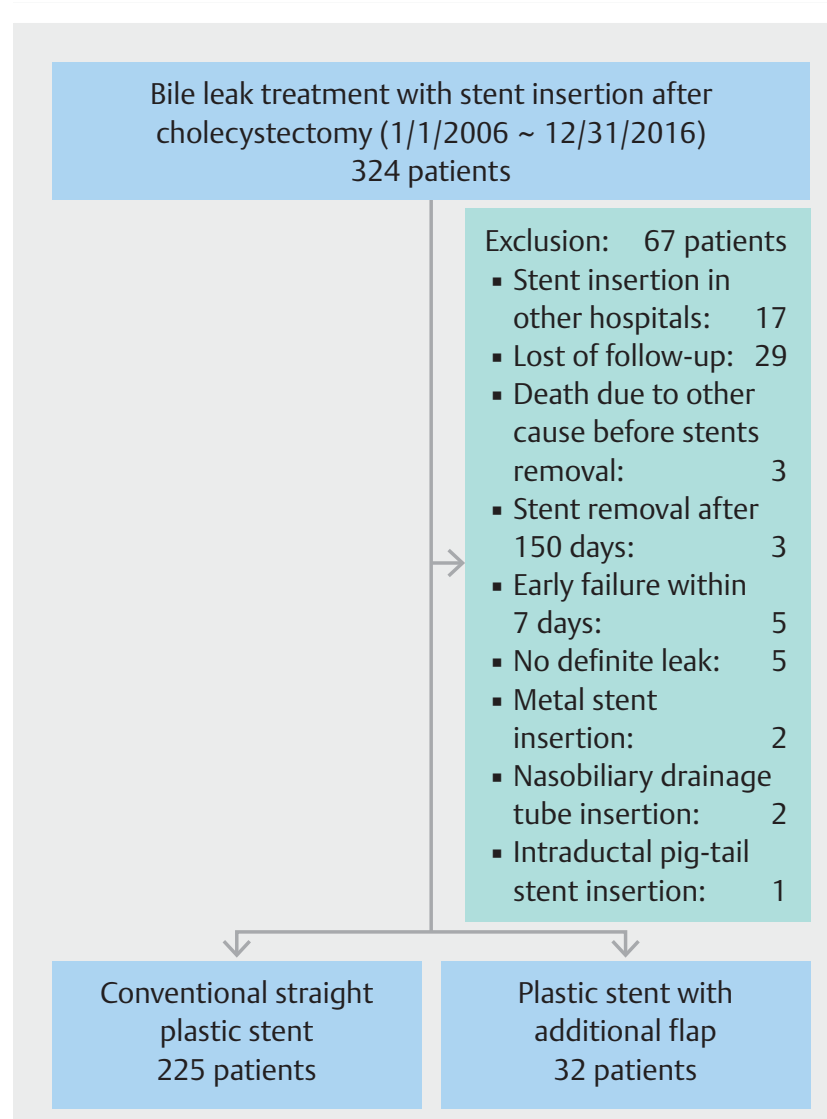

- Fig. 3 Flowchart of patients undergoing ERCP for post-cholecystectomy bile leak.

with early failure were excluded from the analysis of migration rate.

Data regarding endoscopic findings, treatment modalities (stent type, stent size) and outcomes (stent migration, leak resolution) were obtained from a prospectively collected ERCP database, in addition to further retrospective review of the medical record and endoscopic record and saved images. This study was approved by the Indiana University Institutional Review Board (IRB \# 1506123407).

Pearson's chi square test (or Fisher's exact test) was used to analyze the difference of categorical variables, and Man-Whitney $U$ test was used to analyze the difference of continuity variables between two groups. Univariate analysis and multivariate analysis were performed on selected variables for assessing stent migration. $P<0.05$ was considered statistically significant.

\section{Results}

During the study period, 324 patients were referred to our hospital for post-cholecystectomy bile leak and underwent ERCP. Sixty-seven patients were excluded due to stent insertion in other hospitals, lost to follow-up, stent removal after 150 days, death due to other causes before stent removal, early treatment failure within 7 days, or no definite leak on cholangiogram ( $\triangleright$ Fig.3). Thus, there were 257 total patients included
- Table 1 Baseline characteristics of patients undergoing ERCP for post-cholecystectomy bile leak.

\begin{tabular}{|c|c|c|c|}
\hline & \multicolumn{2}{|c|}{$\begin{array}{l}\text { Stent insertion for bile leak } \\
(n=257)\end{array}$} & \multirow[t]{2}{*}{$P$ value } \\
\hline & $\begin{array}{l}\text { Additional } \\
\text { flap stent } \\
\text { group } \\
(\mathrm{n}=32)\end{array}$ & $\begin{array}{l}\text { Conven- } \\
\text { tional stent } \\
\text { group } \\
(n=225)\end{array}$ & \\
\hline Age (year) & $51.8 \pm 19.9$ & $49.9 \pm 17.2$ & 0.514 \\
\hline $\operatorname{Sex}(M: F)(\%)$ & $\begin{array}{l}14: 18 \\
(43.8: 56.3)\end{array}$ & $\begin{array}{l}77: 148 \\
(34.2: 65.8)\end{array}$ & 0.325 \\
\hline Site of bile leak (\%) & & & 0.068 \\
\hline 1. Cystic duct & $21(65.6)$ & $107(47.6)$ & \\
\hline 2. Duct of Luschka & $6(18.8)$ & $95(42.2)$ & \\
\hline 3. Common bile duct & $3(9.4)$ & $13(5.8)$ & \\
\hline 4. Intrahepatic duct & $2(6.3)$ & $5(2.2)$ & \\
\hline 5. $1+2$ & $0(0)$ & $5(2.2)$ & \\
\hline Severity of bile leak (\%) & & & 1.000 \\
\hline 1. Simple bile leak & $29(90.6)$ & $203(90.2)$ & \\
\hline 2. Complex bile leak & $3(9.4)$ & $22(9.8)$ & \\
\hline $\begin{array}{l}\text { Maximal bile duct } \\
\text { diameter }(\mathrm{mm})\end{array}$ & $6.5 \pm 2.4$ & $8.3 \pm 3.0$ & 0.003 \\
\hline $\begin{array}{l}\text { Retained choledocholi- } \\
\text { thiasis }\end{array}$ & $0(0)$ & $31(13.8)$ & 0.019 \\
\hline Bile duct stricture & $0(0)$ & $13(5.8)$ & 0.380 \\
\hline
\end{tabular}

in the analysis. Thirty-two patients were treated with the additional flap stent and 225 patients were treated with conventional plastic stents. Nearly all (255/257) patients had concomitant biliary sphincterotomy with biliary stent placement for management of bile leak.

The baseline characteristics and initial ERCP findings of the two groups are summarized in $>$ Table 1 . There were no statistical difference in demographics including age and sex. Furthermore, there were no differences in the site of bile leak or severity of bile leak. There were differences in the maximum bile duct diameter in the additional flap group compared to the conventional stent group $(6.5 \mathrm{~mm}$ vs. $8.3 \mathrm{~mm}$, respectively, $P=0.003)$ and status of retained choledocholithiasis at time of index ERCP ( $0 \%$ vs. $13.8 \%$, respectively, $P=0.019$ ).

ERCP interventions and outcomes are summarized in $>\mathrm{Ta}$ ble 2 . The combined failure rate of a single endoscopic treatment for all patients was $10.5 \%$ (27/257). The combined stent migration rate for both groups was $15.2 \%$ (39/257). Additional endoscopic therapy with multiple stent insertions in patients with failure of single endoscopic treatment resulted in biliary leak healing in all remaining patients. In the additional flap stent group, the stent migration rate was significantly lower than that in the conventional group $(3.1 \%$ vs. $16.9 \%$, respec- 
- Table 2 ERCP procedures, stent characteristics, and outcomes.

\begin{tabular}{|c|c|c|c|}
\hline & \multicolumn{2}{|l|}{ Stent insertion for bile leak $(n=257)$} & \multirow[t]{2}{*}{$P$ value } \\
\hline & Additional flap stent group $(n=32)$ & Conventional stent group $(n=225)$ & \\
\hline Sphincterotomy performed & $32(100)$ & $223(99.1)$ & 1.000 \\
\hline Stent number & & & 0.147 \\
\hline - 1 stent & $31(96.9)$ & $194(86.2)$ & \\
\hline - 2 stents & $1(3.1)$ & $31(13.8)$ & \\
\hline Stent diameter (Fr) & $9.0 \pm 1.3$ & $8.9 \pm 1.3$ & 0.892 \\
\hline - $5 \mathrm{Fr}$ & $0(0)$ & $4(1.8)$ & \\
\hline . $7 \mathrm{Fr}$ & $6(18.8)$ & $52(23.1)$ & \\
\hline - $8.5 \mathrm{Fr}$ & $8(25.0)$ & $58(25.8)$ & \\
\hline - $10 \mathrm{Fr}$ & $17(53.1)$ & $108(48.0)$ & \\
\hline - $11.5 \mathrm{Fr}$ & $1(3.1)$ & $3(1.3)$ & \\
\hline Stent length $(\mathrm{cm})$ & $9.3 \pm 2.3$ & $8.3 \pm 2.1$ & 0.039 \\
\hline Stent duration (day) & $48.0 \pm 21.2$ & $40.6 \pm 17.1$ & 0.020 \\
\hline Leak healed after first stent session & $32(100)$ & $198(88.0)$ & 0.032 \\
\hline Total stent migration & $1(3.1)$ & $38(16.9)$ & 0.042 \\
\hline \multicolumn{4}{|l|}{ Stent migration type ${ }^{1}$} \\
\hline - Proximal migration & 1 & 10 & \\
\hline - Distal duodenal migration & 0 & 4 & \\
\hline - Partial distal duodenal migration & 0 & 24 & \\
\hline Leak healed according to stent migration & & & 0.393 \\
\hline - Non-migrated & & $193 / 218(88.5)$ & \\
\hline - Migrated & & $37 / 39(94.9)$ & \\
\hline
\end{tabular}

tively, $P=0.042)$. There were no cases of distal migration in the additional flap stent group. There was successful healing of bile leak with the first stent in all additional flap stent group patients $(n=32,100 \%)$ and in $198(88.0 \%)$ of the conventional group $(P=0.032)$. In the conventional group, healing rates were not statistically different between patients with stent migration and without stent migration $(P=0.270)$. However, univariate analysis demonstrated that stent group was not associated with the prevention of stent migration. Only retained choledocholithiasis was associated with stent migration ( $>\mathrm{Ta}$ ble 3). The only noted minor adverse events were erosions or shallow ulcers on the duodenal wall which were induced by stent irritation in five patients with partial stent migration. There were no duodenal perforations or gastrointestinal bleeding from migrated stents.

\section{Discussion}

This study was conducted to evaluate the hypothesis that an additional flap on a plastic stent may decrease the rate of migration in biliary stents placed for bile leak. Anchoring fins on self-expandable metal stents have been associated with favorable anti-migratory effects in previous studies [12,13]. In patients who may be at risk for stent migration, the placement of pigtail stents may be considered, yet this can be limited in nondilated ducts (such as in most bile leaks). Older studies have demonstrated more sludge accumulation in stents with side holes than without side holes, and there is the theoretical risk in our study that the additional flap stent could lead to more stent occlusion due to this $[14,15]$. Fortunately, stents placed for this indication rarely need to be in place for longer than 2 months and therefore rarely occlude.

Based on data from the current study, the total stent migration rate in patients with conventional stent insertion (16.9\%) was higher than previously reported migration rates (up to 
- Table 3 Univariate analysis of factors affecting the migration of stents in bile leak patients.

\begin{tabular}{|c|c|c|c|c|}
\hline Variables & & $\mathrm{n}(\%)^{1}$ & Migration (\%) & Univariate $P$ value \\
\hline \multirow[t]{2}{*}{ Gender } & Male & $91(35.4)$ & $14(15.4)$ & \multirow[t]{2}{*}{0.945} \\
\hline & Female & $166(64.6)$ & $25(15.1)$ & \\
\hline \multirow[t]{2}{*}{ Age (y) } & $\leq 50$ & $135(52.5)$ & $19(14.1)$ & \multirow[t]{2}{*}{0.359} \\
\hline & $>50$ & $122(47.5)$ & $20(16.4)$ & \\
\hline \multirow[t]{2}{*}{ Group } & Additional flap stent & $32(12.5)$ & $1(3.1)$ & \multirow[t]{2}{*}{0.074} \\
\hline & Conventional stent & $225(87.5)$ & $38(16.9)$ & \\
\hline \multirow[t]{5}{*}{ Site of bile leak } & Cystic duct & $128(49.8)$ & $24(18.8)$ & \multirow[t]{5}{*}{0.199} \\
\hline & Duct of Luschka & $101(39.3)$ & $12(11.9)$ & \\
\hline & Common bile duct & $16(6.2)$ & $1(6.3)$ & \\
\hline & Intrahepatic duct & $7(2.7)$ & $2(28.6)$ & \\
\hline & Cystic duct + Duct of Luschka & $5(1.9)$ & 0 & \\
\hline \multirow[t]{2}{*}{ Severity of bile leak } & Simple bile leak & $232(90.3)$ & $36(15.5)$ & \multirow[t]{2}{*}{0.643} \\
\hline & Complex bile leak & $25(9.7)$ & $3(12)$ & \\
\hline \multicolumn{2}{|l|}{ Retained choledocholithiasis } & $31(12.1)$ & $9(29.0)$ & 0.026 \\
\hline \multicolumn{2}{|l|}{ Bile duct stricture } & $13(5.1)$ & $0(0)$ & 0.999 \\
\hline \multicolumn{2}{|l|}{ Sphincterotomy } & $255(99.2)$ & $39(15.3)$ & 0.999 \\
\hline \multirow[t]{2}{*}{ Bile duct diameter (mm) } & $\leq 7$ & $107(50.2)$ & $12(11.2)$ & \multirow[t]{2}{*}{0.139} \\
\hline & $>7$ & $106(49.8)$ & $20(18.9)$ & \\
\hline \multirow[t]{2}{*}{ Stent diameter $(\mathrm{Fr})$} & $\leq 7$ & $61(23.7)$ & $13(21.3)$ & \multirow[t]{2}{*}{0.076} \\
\hline & $>7$ & $196(76.3)$ & $26(13.3)$ & \\
\hline \multirow[t]{2}{*}{ Stent length (cm) } & $\leq 7$ & $115(44.7)$ & $18(15.7)$ & \multirow[t]{2}{*}{0.848} \\
\hline & $>7$ & $142(55.3)$ & $21(14.8)$ & \\
\hline \multirow[t]{2}{*}{ Stent duration (week) } & $\leq 6$ & $168(65.4)$ & $25(14.9)$ & \multirow[t]{2}{*}{0.532} \\
\hline & $>6$ & $89(34.6)$ & $14(15.7)$ & \\
\hline
\end{tabular}

$10 \%)[9,10]$. We believe this is because the indication for stent placement in this study is in post-cholecystectomy bile leak, which in the majority of cases is not associated with stricture. Thus, the stent has less to anchor itself to within the bile duct. In our study, there were significantly fewer instances of stent migration in the group of patients treated with a stent with an extra antimigration flap. Although the additional flap stent group was not associated with the prevention of stent migration on univariate analysis, we suspect there would be different results with larger numbers. Furthermore, we found that the rate of leak resolution after a single ERCP intervention was superior in the group of patients who were treated with a stent with an extra antimigration flap. This is an important finding, as patients who have leak resolution after a single ERCP require fewer procedures and likely decrease healthcare costs compared to those that require multiple ERCPs to accomplish leak resolution. We hypothesized that stent migration would be associated with delayed or failure of biliary leak resolution. We did not see that in this study, however. In the conventionally treated group, there was no significant difference in the rates of leak resolution in the patients with migrated and nonmigrated stents. Stent migration in this study did create duodenal erosions or shallow ulcers in five cases, which could predispose to bleeding or perforation. These were not seen in this study. Theoretically, however, a decreased rate of migration with an extra antimigration flap may prevent the very rare complication of migrated stent-induced perforation of the duodenum or other intestinal wall.

One limitation of this study is that it is retrospective in nature. Also, there were substantially fewer patients in the modified stent group $(n=32)$ compared to the conventional stent group $(n=225)$. Also, there were baseline differences (maximal bile duct diameter, retained choledocholithiasis) in the groups of the patients, and thus they may not have been equivalent groups of patients. 
Because this is a proof of concept study and the number in either group would not be robust enough to match cases, we didn't do a propensity matching analysis by using multiple variables: demographics, type of leak, endoscopist, stent diameter, stent length, duct diameter, number of stents, and presence of sphincterotomy. Future prospective studies will better be able to address any potential bias that may be present in the current study.

\section{Conclusion}

In conclusion, our study demonstrates improved performance with regard to leak resolution and stent migration in patients treated with a plastic biliary stent with an extra antimigration flap, compared to standard therapy with conventional plastic biliary stents. The addition of a flap is a simple scalpel cutting technique which takes less than one minute, and incurs no additional cost to the standard conventional stent. If further data supports the improvement of performance with this stent type, either endoscopists may find this a simple stent modification to perform at the time of the procedure or a commercial company may consider manufacturing such a stent. A prospective, randomized and controlled multicenter study would further define the benefits of this approach to endoscopic management of bile leaks.

\section{Competing interests}

None

References

[1] Navarrete C, Gobelet JM. Treatment of common bile duct injuries after surgery. Gastrointest Endosc Clin N Am 2012; 22: 539- 553
[2] Barkun AN, Rezieg M, Mehta SN et al. Postcholecystectomy biliary leaks in the laparoscopic era: risk factors, presentation and management. Gastrointest Endosc 1997; 45: 277 - 282

[3] Davids PH, Rauws EA, Tytgat GN et al. Postoperative bile leakage: endoscopic management. Gut 1992; 33: 1118-1122

[4] Foutch PG, Harlan JR, Hoefer M. Endoscopic therapy for patients with a post-operative biliary leak. Gastrointest Endosc 1993; 39: 416- 421

[5] Ryan ME, Geenen JE, Lehman GA et al. Endoscopic intervention for biliary leaks after laparoscopic cholecystectomy: a multicenter review. Gastrointest Endosc 1998; 47: 261-266

[6] Katsinelos P, Kountouras J, Paroutoglou G et al. A comparative study of $10-\mathrm{Fr}$ vs. 7-Fr straight plastic stents in the treatment of postcholecystectomy bile leak. Surg Endosc 2008; 22: 101-106

[7] Pitt HA, Sherman S, Johnson MS et al. Improved outcomes of bile duct injuries in the 21st century. Ann Surg 2013; 258: 490-499

[8] Rustagi T, Aslanian HR. Endoscopic management of biliary leaks after laparoscopic cholecystectomy. J Clin Gastroenterol 2014; 48: 674678

[9] Johanson JF, Schmalz M], Geenen JE. Incidence and risk factors for biliary and pancreatic stent migration. Gastrointest Endosc 1992; 38: $341-346$

[10] Haapamäki C, Kylänpää L, Udd M et al. Randomized multicenter study of multiple plastic stents vs. covered self-expandable metallic stent in the treatment of biliary stricture in chronic pancreatitis. Endoscopy 2015; 47: 605-610

[11] Coelho-Prabhu N, Baron TH. Assessment of need for repeat ERCP during biliary stent removal after clinical resolution of postcholecystectomy bile leak. Am J Gastroenterol 2010; 105: 100 - 105

[12] Park do H, Lee SS, Lee TH et al. Anchoring flap versus flared end, fully covered self-expandable metal stents to prevent migration in patients with benign biliary strictures: a multicenter, prospective, comparative pilot study (with videos). Gastrointest Endosc 2011; 73: 64-70

[13] Lalezari D, Singh I, Reicher $S$ et al. Evaluation of fully covered self-expanding metal stents in benign biliary strictures and bile leaks. World J Gastrointest Endosc 2013; 5: 332-339

[14] Coene PP, Groen AK, Cheng J et al. Clogging of biliary endoprostheses: a new perspective. Gut 1990; 31: $913-917$

[15] Rey JF, Maupetit P, Greff M. Experimental study of biliary endoprosthesis efficiency. Endoscopy 1985; 17: 145-148 